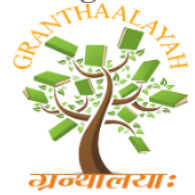

INTERNATIONAL JOURNAL OF RESEARCH GRANTHAALAYAH A knowledge Repository

Science

\title{
TRIBAL ART \& THEIR RITUALISTIC, UTILITARIAN, INDIVIDUALISTIC IMPORTANCE: A GLIMPSE OF TRIBAL ART
}

\author{
Dr. Deepak Salvi *1 \\ ${ }^{* 1}$ Assistant Professor, Drawing \& Painting, Government College, Sagwara Affiliated by Govind \\ Guru Tribal University, Banswara, India
}

\begin{abstract}
Bhil tribes have a long history of their existence. Bhil love arrow and bow and it is believed that their name emerged from Dravid language word "billu" means bow and arrow. Their reference is in old literature Ramayana (in context of Shabri) and Mahabharata in context of Eklavya. In Sanskrit literature Bhil tribe occurs in Katha Sarit Sagar (600 A.D.). The traditional abodes of the tribes are hills and forests, and their popular names, meaning either the people of forest and hill or original inhabitants, are: Vanyajati (castes of the forests), vanvasi (inhabitants of forests), pahari (hill dwellers), adimjati (original communities), adivasi (first settlers), janjati (folk people), anusuchit janjati (schedules tribe). Amongst all these terms adivasi is known most extensively. Generally, the uppermost section of the enclosure, above a wavy line with geometric motifs.
\end{abstract}

Keywords: Tribal Art; Importance; Ritualistic.

Cite This Article: Dr. Deepak Salvi. (2019). "TRIBAL ART \& THEIR RITUALISTIC, UTILITARIAN, INDIVIDUALISTIC IMPORTANCE: A GLIMPSE OF TRIBAL ART." International Journal of Research - Granthaalayah, 7(11SE), 95-98. https://doi.org/10.5281/zenodo.3585079.

\section{Introduction}

The aim of this paper is to examine the changes revolving around Tribal art form. This study employs content analysis and is based on primary \& secondary sources such as books, journal articles, tribal literature and monographs. The main objectives of this study are to describe the ritualistic, utilitarian, individualistic importance of this tribal art form; to discuss the changes that Tribal art has undergone; to locate the current status of this art form in the context of tribal development and to discuss the contributory factors responsible for change. The impact of changing society is visible in the themes of Tribal paintings. However, need of the hour is to preserve their art and use it. 


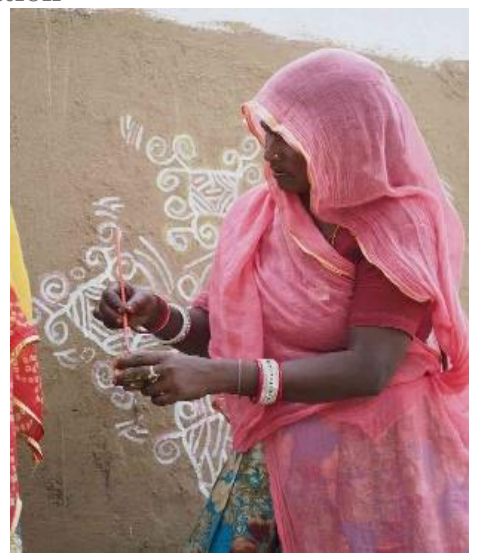

Art in all its dimensions tribal, rock, ancient or contemporary is today a well-established discipline all over the world. It is clear that it is important to study in detail this aspect of the cultural heritage of humankind. The rich cultural world of tribal arts is an invaluable component of the mosaic of Indian art. Tribal art generally reflects the creative energy found in rural areas that acts as an undercurrent to the craftsmanship of the tribal people. Tribal art ranges through a wide range of art forms, such as wall paintings, tribal dances, tribal music, and so on. The religious beliefs, ritual and the social organization of a tribe may greatly influence art. In case of tribal painting, preserving the art form through its commercial usage may be one way of propagating it; however, it is important to take into account the sentiments of the people. The benefits of its commercial use should directly reach the tribes practicing this art form.

All Tribal art forms and culture forms have an ethnic nature. The myths of a particular region form the plot of these art forms. These art forms are the totality of the cultural experiences of particular regions. It is the highly popular and religious cultural groups that help them rise beyond time. These Tribal art forms maintain their ethnic nature through which they make socialization possible; they regulate them and harmonize them with other communities. In the center they have a smaller rectangle where they make orange dots with the fingers, called Tipna, which is done at the end of the ritual when the painting is complete. On top, the Sun, the Moon, monkeys and other figures are drawn. Horizontally, there are three rows, and the central row of Pithora and Tipna are the most important.

Some pictographic motifs symbolising joy and pride like the sun, flowers, trees, human figures, peacocks, palanquins, etc, all a spontaneous result of man's close association with his immediate surroundings auspicious designs also consist of two interlaced triangles, signifying Saraswati, the goddess of learning. Traditionally, Tribal art forms, though sometimes purely decorative, were used to mark different occasions such as celebrations, events to pacify malevolent deities or forces of nature, thanksgiving, harvests, and the birth of a child, puberty, marriage and cultural festivals. Painted narratives on various surfaces, such as walls, floors, cloth, wood and paper became important sources of knowledge about local mythology, deities, heroes, epics, folktales and customs. 


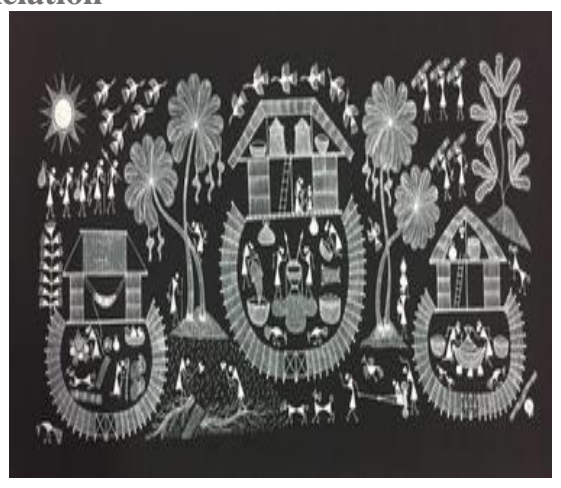

A variety of techniques are prevalent for making the art forms. Generally, the designs are made freehand, where the artist evolves the form as the work is in progress. Hence, the forms, beginning at the centre with a dot expands in concentric patterns of geometrical shapes of circles, squares, triangles, straight lines and curves. It is a natural way of drawing, beginning at the centre, growing larger with each repetition of a pattern.

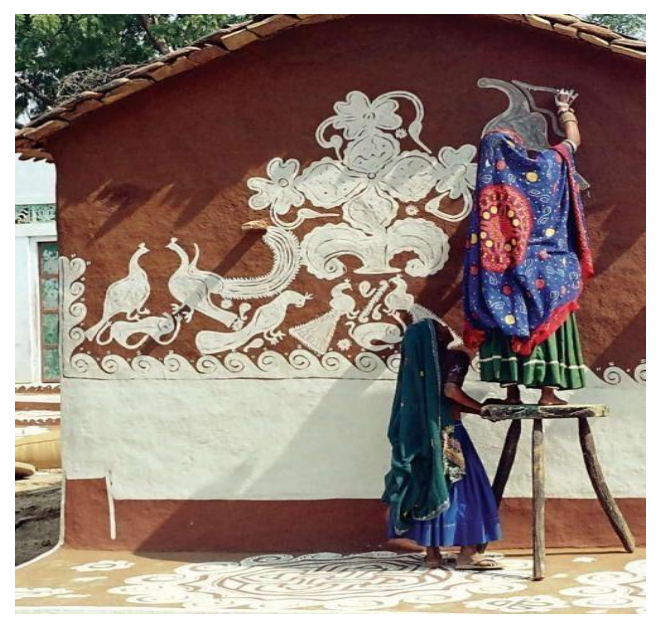

As with most tribal art forms, all ingredients used for making tribal paintings are natural. All the Indian zodiacal signs are drawn, especially the Sun and the Moon. Like in all other creative expressions, nature has been the source of inspiration for many of the designs whether in symbolic or stylized form. Vegetable pigments derived from leaves, flowers and other forest produce are mixed with milk to prepare the colors. Unlike other artistic tribes like Warli, the Tribal painters are male dominant. These paintings have significance in the lives these tribes and executing the Tribal paintings in their homes brings peace, prosperity and happiness. In context of tribal art, it is relevant to note whether a design is representing human beings, zoomorphic (animals), plants, a design based on a feature no longer functional. The ritualistic painting is believed to bring peace, prosperity and happiness to the family. Since the last four decades or so Folk and Tribal art of India has evolved to not only include traditional aesthetics but also encompass contemporary visuals and attitudes making the individual artist the center of their creation and vision. The focus is on individual artist to give their art a new voice and lead it to the new phase of global art and help in the revival of these art forms. 
The factors responsible for changes in the tribal art form are due to assimilation, modernization and globalization. In their eagerness to be included into the mainstream the tribal are adopting the ways and means of caste communities and in the process moving away from their cultural roots. The course of modernization has led to development of means of transport and communication which has propelled contact with and influence of the outside world on them. In addition, the advent of globalization has opened up market economy and created avenues for using tribal art and craft for commercial purposes. As a result of the impact of globalization these tribal are utilizing their art form for commercial purposes.

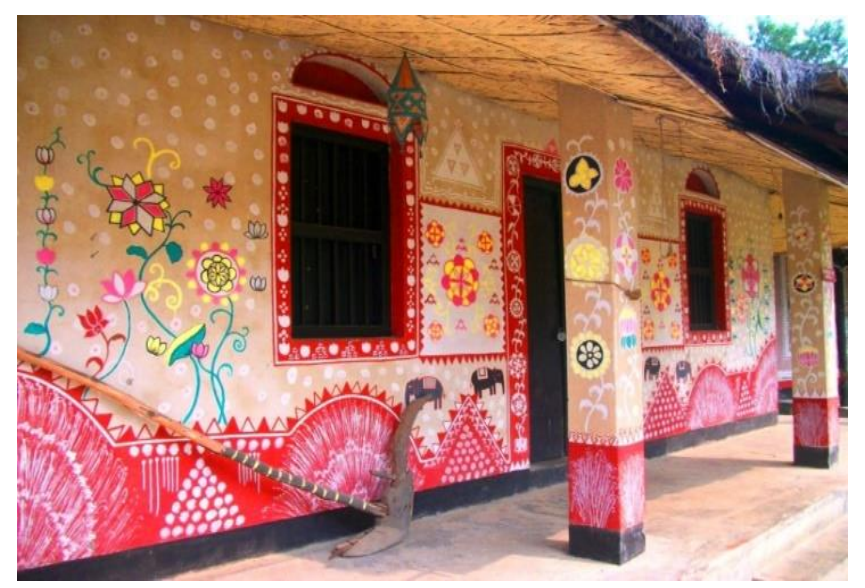

When we understand the relationship between cultures and their ancient religious beliefs in particular autochthonous cultures and their animist forms of worship, we realize that forcible destruction of their cultures and traditional life ways and religious expressions are in fact religious repression and that forcing change on them by the dominant order is in fact religious conversion. For decades, India's tribal communities have been creating unique paintings, featuring animal figures and nature-based themes, which document their distinct cultures and beliefs. In this research paper, the Centre presents a small collection of Tribal art forms. The purpose is to inspire research scholar and art- critics to make creative expression a part of their daily life and to share the joy of decorative Tribal art forms which have been passed on from generation to generation. In the floor designs that are given in this package, you will notice that nature in all its manifestations figures prominently. Even in those designs that are made for specific religious or social ceremonies, stylised depictions of the Sun, the Moon, birds, flowers and trees form part of the design. The Indian lives in harmony with nature. All his creative expressions are directly influenced by his immediate environment. The decorative art of floor and wall designs express this innate urge for artistic expression characteristic to the Indian psyche.

Tribal art form depicts human forms, animals, plants, sacred and transcendental elements and designs pleasing to the eye. Fundamentally, the tribal art and crafts correspond to three types, namely, ritualistic-used in rites associated with some beliefs and mystical ideas; utilitarian- usage of objects, social customs and in everyday practices; and lastly, individualistic- made to express feelings and emotions of the craftsmen. 